\title{
CONTRIBUCIONES A LAS \\ CIENCIAS SOCIALES
}

\section{EL CONOCIMIENTO SOCIAL EN LA REGENTA: UNA CONCILIACIÓN ENTRE LA SOCIOLOGÍA Y LA LITERATURA}

Para citar este artículo puede utilizar el siguiente formato:
$\begin{array}{r}\text { Sabrina Maazouz } \\ \text { Doctoranda. Universidad de Argel } 2 \\ \text { ORCID } \\ \text { sabrina.maazouz@univ-alger2.dz }\end{array}$
Sabrina Maazouz: "El conocimiento social en la regenta: una conciliación entre la sociología y la
literatura”, Revista Contribuciones a las Ciencias Sociales, (Vol 1, № 8 octubre-diciembre 2021, pp.
36-46). En línea:
https://doi.org/10.51896/CCS/BDHN4993

\section{RESUMEN}

En este humilde artículo entraré a fondo en dos aspectos: por una parte, la correspondencia entre sociología y literatura, y por la otra, La Regenta como novela sociológica, como documento histórico enriquecedor donde valores, normas y símbolos se confluyen para forjar un conjunto social. Es fantástica la relación que mantiene esta dicotomía del conocimiento del ser humano, tanto sociológica como literatura colaboran para garantizar mejor comprensión de la sociedad. La Regenta, una novela realista del siglo XIX, es un modelo literario inestimable de esta complementariedad entre lo científico y lo artístico, y que me servirá para ilustrar, en las siguientes páginas, como el novelista puede adoptar el disfraz de un sociólogo, sin dejar de ser sí mismo.

Palabras clave: Sociología, literatura, Clarín, sociedad, La Regenta, iglesia, burguesía, realismo.

\section{SOCIAL KNOWLEDGE IN LA REGENTA: A CONCILIATION BETWEEN SOCIOLOGY AND} \section{LITERATURE}

\section{ABSTRACT}

In this humble article I will go deeply into two aspects: on the one hand, the correspondence between sociology and literature, and on the other, La Regenta as a sociological novel, as an enriching historical document. The relationship that maintains this dichotomy of human knowledge is fantastic, both sociology and literature collaborate to ensure a better understanding of society. La Regenta, a 19th century realist novel, is an invaluable literary model of this complementarity between the scientific and the artistic, and it will serve to illustrate, in the following pages, how the novelist can adopt the disguise of a sociologist, without leaving to be himself.

Keywords: Sociology, literature, Clarin, society, La Regenta, church, bourgeoisie, realism. 


\section{INTRODUCCIÓN}

En la literatura nos vemos reflejados, y a ella nos huimos de las realidades que negamos y en las que estamos anegados. Es como un hogar psicológico que nos acoge incondicionalmente. De este espacio ficticio, se destaca La Regenta como prueba viva de la intensa identificación que un lector pueda sentir al zambullirse en la lectura de una novela. En Vetusta, "la heroica ciudad que dormía la siesta", viven unos tipos de fenómenos universales y atemporales que Clarín, el provinciano universal, forja en su inmejorable novela, La Regenta. Son aquellos personajes que sufren y hacen sufrir por culpa de la naturaleza social, y él es el hombre que novela criticando sutilmente las fuerzas ambientales que rigen las conductas de los individuos en contra de sus aspiraciones personales, y sin nunca pretender sublimar el determinismo, este choque parece inevitable y la caída moral es muy probable. Y como Zola recalca, una obra literaria no puede existir fuera de su contexto, porque el creador de la literatura se inspira necesariamente de un mundo tangible para armar la infraestructura de su ficción, donde se fusionan tiempos, espacios, costumbres, valores y filosofías, y se responsabiliza de exorcizar a su sociedad de los males imperantes. De ahí que la literatura se convierte en un auténtico compromiso social y se consolida como conocimiento sociológico.

\section{Sociología versus literatura:}

Los primeros sociólogos, tal como Marx y Weber, se destacan por la grandilocuencia de su expresión científica, tan comparable con las novelas, la escritura de Ortega también se puede leer como literatura " científica". Sin embargo, con el paso del tiempo se fue perdiendo poco a poco esta peculiaridad a favor del cientificismo de la sociología. Lamo de Espinosa (2019) recalca la escasez de novelas escritas por sociólogos clásicos, y hace tres excepciones bastante interesantes: los escritos de Francisco Ayala, Les lois de l'imitation de Gabriel Tarde y La Regenta de Clarín. De hecho, me sorprende que Espinosa considere a Clarín como un sociólogo o " científico social", porque, aunque esta confesión pueda servir el horizonte mi trabajo, por pura honestidad intelectual rechazo esta categorización. No obstante, concuerdo con él en lo que toca La Regenta como una novela que comparte los mismos fines de la sociología: constar el impacto de lo social en lo humano. Desentrañar la sociedad es una costumbre humana demasiado remota, pero esta práctica, sumamente arbitraria y subjetiva, requiere un conjunto de principios dictados por la razón y la lógica. Así fue cómo surgió la sociología a mediados del siglo XIX como una ciencia, disciplina, o como insisto yo, una metodología para descifrar la complejidad de las relaciones interhumanas y los fenómenos sociales. No obstante, esta sociología no se dirige a la sociedad, a la masa, sino a una cierta élite intelectual, los sociólogos, que son aptos para entender su lenguaje científico (Gaspar, 2009). Esta exclusividad del entendimiento hace ensanchar la distancia entre el individuo (actor) y el sociólogo (observador), en vez de minimizarla como es debido. Si bien, no se puede negar la valiosa contribución de la sociología " a la ingeniería social, al management macro de las sociedades modernas, pero poco a la sabiduría colectiva." (Espinosa, 2019, p. 100). Sin embargo, cuando este actor no se encuentra a la altura de asimilar este conocimiento científico, busca otras formas para 
entenderse a sí mismo, a los demás y así a las motivaciones personales que brotan de la naturaleza social. Me refiero, sin duda, a las formas artísticas tales como el teatro y la novela. Esta última se manifiesta, a cierta medida, como un relato voluminoso para poder así abarcar el máximo de la realidad social, junto a otros objetivos que sólo dependen de la voluntad del novelista.

\subsection{La novela sociológica:}

En el siglo XX, precisamente de la Escuela de Chicago, varios sociólogos adoptaron un estilo novelesco en escritos que pretenden ser sociológicos, tal como los de Nels Anderson y Shutherland. Curiosamente, mientras los sociólogos son muy cuidadosos en su observación por miedo a ser tachados por fabuladores, los novelistas tienden conscientemente a escribir ficción sociológica, esto lo que hace de la novela "un remedo de la misma sociología a la que sustituye incluso con ventaja. Y así, es imposible conocer (...) la España de la Restauración sin Pérez Galdós o Clarín, o el Madrid barriobajero sin Baroja y La Busca" (Espinosa, 2019, p. 90), de modo que tanto novela como sociología se inspiran de la misma fuente, la sociedad, pero se expresan diferentemente. Es más, a decir verdad, que de los mismos ingredientes ellas cocinan distintos platos, siendo la novela realista más digna de ser considerada como sociológica, aunque no se puede reducir la literatura a la sociología, porque en esta el narrador novelesco puede silenciarse por completo, mientras que en la otra vemos el mundo por los ojos del personaje. Según Subero, "el novelista tiene que instrumentar una incesante búsqueda expresiva (...). El valor histórico de la novela tiene que ser entonces un valor sincrónico" (1974, p. 493). Sofia Gaspar (2009, p. 102) sostiene "a través de los personajes tendríamos noticias de la complejidad de la naturaleza humana; [...] y a través del contexto sabríamos algo sobre las claves de un mundo". Todavía cabe señalar que Espinosa (2019, p. 102) también afirma "las novelas se hacen a medida que se escriben, los personajes adquieren vida, desarrollan su propia lógica, su propia sociológica ", así que un novelista es tanto un actor social como un observador social. Este desdoblamiento generoso por parte del cual es lo que garantiza que un lector conozca toda una sociedad a través de la novela. En resumen, Novela y Sociología, teniendo el mismo norte, su engranaje y su público son racionalmente distintos.

\subsection{Clarín ¿novelista o sociólogo?}

Clarín, el provinciano universal, en su Regenta nos forja el mundo de Vetusta, Oviedo, pero las realidades presentes no son exclusivamente vetustenses, sino españolas, e incluso europeas. Es un microcosmo que refleja, consciente o inconscientemente, el mundo entero, es la Vetusta universal. Pero ¿Qué hace exactamente Clarín en su Regenta? Primero, que nos pongamos de acuerdo sobre el oficio de un sociólogo, Pedro Blois (2014, p. 92) dice que " la función primaria de un sociólogo es producir verdades objetivas, racionales y empíricamente fundamentales sobre el mundo social". En literatura, el realismo no logra una investigación objetiva de la sociedad que le toca describir porque, aunque objetividad sea el norte del novelista, es ineludible no dejar caer un pedazo de su propia visión del mundo. Espinosa (2012) alega que la novela realista es tanto literatura como sociología, pero esta última tiene como ventaja de presentar casos bien definidos y delimitados. La Regenta, como ejemplo, trata el adulterio y nos explica porque una mujer española decimonónica 
comete tal aberración social, pero no nos habla de las tasas del adulterio en España, ni abarca la totalidad de sus motivos. Así que la novela realista es una sociología parcial y selectiva.

\section{La Regenta como documento social:}

El proceso histórico de la Restauración se inició en 1874, Clarín sitúa los hechos de La Regenta en la época entendida entre 1877 y 1880. La inclusión de este contexto es axiomática, pero lo sorprendente es el detallismo del autor en la novelización de este conjunto. Clarín se afana en su misión socio-literaria, y sin lugar a duda, lo logra. ¿Cómo? Esto es exactamente lo que demostraré en las siguientes páginas. Pero, antes de seguir adelante en este estudio, me gustaría señalar que, en el presente artículo, junto al contexto, abordaré tres puntos de extrema trascendencia relativa; la mujer, la aristocracia y la iglesia, plasmados por tres personajes que dominan la acción novelesca; Ana, Álvaro y Fermín.

\subsection{El panorama social:}

\subsubsection{La Restauración Alfonsina:}

La Restauración significó la rescisión de las libertades que La Gloriosa intentó inculcar generosamente en la conciencia española, las de la religión y de la enseñanza, que eran los matices de los sueños liberales enterrados una vez que se instaló nuevamente el Antiguo Régimen en 1874. Clarín, uno de " los hijos del liberalismo sofocado", descargó su frustración nacional en infinitos artículos y críticas, pero su Regenta es la que representa el auge expresivo del disgusto, la rabia y la decepción clarinianos. (Caro Baroja, 2008). Un pronunciamiento, el de 29 de diciembre de 1874, cambió el destino de los españoles poniendo fin al Sexenio revolucionario, a la democracia, al libre albedrío, a los ideales de Clarín, e hizo resucitar un sistema absolutista, opresor, delicuescente y desfasado. Oligarquía, caciquismo y capitalismo eran los tres factores que colorearon la situación sociopolítica a partir de la fecha mencionada. La burguesía se alejaba paulatinamente de su raigambre liberal para adscribirse a la actual estructura establecida, la conservadora impulsada por Cánovas. Esta burguesía misma que acometía la aristocracia desde los albores del siglo, ahora se inspira de ella para forjar su nueva identidad social. Sorprendentemente, tanto la aristocracia como la iglesia no pudieron recuperar la totalidad de su poder histórico, a pesar de que la Restauración significó abiertamente la vuelta a lo antiguo. Por ello, ambos se apoyaron ante esta contrariedad que tuvieron en común, como ya lo habían hecho antes. La alta burguesía se esforzaba, a diferencia de la baja burguesía, en introducirse entre esta clásica dicotomía de la sociedad española, principalmente para guardar las apariencias y mantener una imagen de corrección. (Oleza, 2012).

\subsubsection{Vetusta, el microcosmo universal:}

En la tan voluminosa Regenta, vemos cómo la sociedad determina e influye en el destino de los personajes, que toman diferentes direcciones en busca de lo mismo; el poder, uno polivalente. 
Cuando Ana Ozores acude a la religión, ella busca consuelo, pero también busca poder, un poder que no logra alejarla del adulterio, por más que ella lo intenta. Esta caída moral es tanto la culpa de la adúltera como la de la sociedad, esta última que sobre la cual Clarín no nos ahorra ningún detalle para describir su maligna naturaleza, su escandaloso fariseísmo y su vulgar dejadez. Ana no sólo busca poder, sino que ella misma se convierte en un objeto de poder. Vetusta nos hace entender que quien tiene a esta mujer, conjuntamente tendrá el poder sobre ella. Esta cosificación de Ana Ozores, a cierto punto despectiva, crece y se fortalece debido a la rivalidad entre don Álvaro y Fermín de Pas. $\mathrm{O}$, mejor dicho, entre la burguesía triunfante y el clero exánime. Ambos hombres se pelean por una mujer prohibida, en una lucha abyecta e innoble que no respeta la santidad del cuerpo de una mujer casada. La clásica pugna entre religión y política, alevosía, falsedad, seducción, sexo, deshonestidad y letargo "heroico" conforman una miniatura social que finge ser la más honesta, que, como España de la Restauración, ella es una ciudad voluntariamente bloqueada, una ciudad que rechaza el cambio y se contenta en su degradante abulia. Aquí y desde la torre de la catedral se vigilan los movimientos de los vetustenses, y a menudo se adivinan sus próximos pasos, unos se dirigen a ella, otros al Casino, cada cual siguiendo su instinto o lo que le dicta su averiada conciencia. El Casino es una contraparte sustancial, es el espacio burgués y el templo de los que no tienen religión, donde muchos personajes se instalan para idolatrar el juego, principalmente, el juego soez de la inmoralidad.

\subsection{Prototipos sociales:}

\subsubsection{Fermín, la cara de la iglesia:}

La Restauración era un periodo de larga tregua canovista entre conservadores y liberales, de inmovilidad y de letargo nacional. No hubo grandes cambios, ni a favor de la iglesia ni de la sociedad. Reinaba la paz en su extrema falsedad. No obstante, la clase clerical pudo triunfalmente imponerse, insisto, no tanto como antes, pero su participación fue a menudo tomada en consideración. Las reiteradas guerras revolucionarias, hijas de la llustración y la Revolución Francesa, debilitaron los pedestales de la iglesia católica en España, que volvía a imperar sobre el destino nacional durante la Restauración una vez que los conservadores tomaron el poder (Bártová, 2016). Y aunque dominaba la sociedad, esta última se dejó secularizar, en especial, al notar la indiferencia clerical hacia los pobres y los obreros en general. En un estudio sociológico, Moliner Prada (2011) explica que la sociedad se dio cuenta que se fue creando una religión dedicada exclusivamente a los nobles y ricos, hecho que desacreditó la integridad de la iglesia. Por ello, no era nada raro que los obreros actuaran en contra de la cual. La insatisfacción del proletariado de la lucratividad o comercialización de la religión se transformó en el PSOE, creado en 1879, uno de los primeros partidos anticlericales (Moliner Prada, 2011). ¿La culpa de quién? No pretendo dar juicios subjetivos, pero, obviamente, la de la iglesia de la Restauración que deformó la moral a favor de sus intereses personales. Pero ojo, este anticlericalismo no significa el rechazo de la religión cristiana, sino de las prácticas adoptadas por los clérigos de aquel entonces. En La Regenta, Clarín cuenta la vuelta de dos poderes; la iglesia y la aristocracia, esta como la nueva vestimenta de la nobleza decadente fusionada con la alta 
burguesía, y la otra como la domesticadora de los miembros sociales, la única capaz de exorcizar a sus almas de los vicios. Pero antes de preguntar si tuvo éxito en su proyecto, veo necesario cuestionar la integridad de la tentativa. ¿que hizo la iglesia vetustense para sus seguidores? La realidad literaria en La Regenta en este caso no diferencia de la versión verídica. Como he señalado anteriormente, Sofía explica que los autores usan personajes contextualizados para hacer un estudio sociológico, parece que Clarín sigue esta metodología. Fermín de Pas es el intérprete de la Iglesia de finales del siglo XIX. Él es el sacerdote que se encuentra en la cima del reconocimiento social por parte de la aristocracia. Es tratado como un Dios, como un ser infalible. La Encimada es el barrio donde viven los aristócratas y donde La torre de la Catedral reposa su silueta, es el paraje que simboliza esta alianza egoísta, que aparca a los pobres y les niega el valor de la existencia. "El buen vetustense era de la Encimada. Algunos fatuos estimaban en mucho la propiedad de una casa, por miserable que fuera, en la parte alta de la ciudad, a la sombra de la catedral" (La Regenta, 1999, p. 82). Cabe mencionar que esta aristocracia literaria está compuesta por Ana Ozores y su esposo, los Vegallana y los Carraspique. Fermín asiste a todos los eventos familiares, sociales y prestigiosos de estas familias, y aunque sea incondicional, su presencia sirve la imagen, como un maquillaje de la hipocresía palpitante en sus espíritus. Esto es lo que importa; la apariencia. De estas familias aristócratas, Los Carraspique son las que sufren el peso de este ridículo fariseísmo de Fermín siguiendo ciegamente sus consejos hasta perder a su propia hija. Como ya es sabido, las niñas tenían dos opciones tradicionales; el matrimonio o el convento, y Fermín se atreve a determinar el destino de las dos hijas de la familia llevándolas al convento, donde los requisitos de la higiene son estridentemente ausentes. Cae la niña Rosita enferma por hacerse una monja, y muere por la contumacia del sacerdote que prohíbe su rescate. Cuando el médico dice "si la niña sigue respirando en aquel medio... no hay salvación, pero si se la saca de allí... tal vez haya esperanza" ( La Regenta, 1999, p. 376). Fermín rechaza fríamente esta posibilidad que parece amenazar la infalibilidad de la iglesia, aunque cuesta la vida de una joven inocente. No obstante, esto no es lo que le angustia al sacerdote tras tal conversación, es su ego que se quema para entender cómo un " hombre de ciencia" se atreve a cuestionar sus decisiones "El Magistral miraba al médico con gran curiosidad y algo de asombro. "¿Cómo aquel hombre de tan escasas luces discurría así en tal materia? (La Regenta, 1999, p. 380). También se preocupa por la reputación de la iglesia (no de su integridad) y por lo que dirá la gente tras la prevista muerte de la niña, por ello prepara silenciosamente su plan de rescate, ahora ya no insiste en convertir las dos otras hijas en monjas, y convence la madre que la vida de Rosita es el sacrificio que le debe a Dios. Rosita es de Dios, no es suya, nunca lo fue: "Lo principal era mirar si había escándalo en precipitarse y tomar medidas que alarmasen a la opinión. Por culpa de ellos, por culpa de un excesivo cariño" (La Regenta, 1999, p. 381). Fermín concluye su desastre diciendo "si es preciso sufrir por bien de la fe una prueba terrible, se sufrirá; porque el nombre de cristiano obliga a eso y a mucho más" (La Regenta, 1999, p. 383). Es él el antagonismo de la caridad y la misericordia religiosa. Cuando los niños pobres se acercan a Fermín para besarle las manos, él siente repugnancia que no es digna de un sacerdote honrado, dice el narrador "continuó dando vueltas y limpiándose la mano besada por la chusma. Le molestaba mucho el pringue, y en el pilón de una de las fuentes se lavó un poco los dedos." (La 
Regenta, 1999, p.469). Fermín es el reflejo auténtico de la mentalidad religiosa de la Iglesia que imperaba en España de la Restauración, escandalosamente clasista, discriminatoria, vacía, desconsiderada e interesada.

\subsection{2. Álvaro, la cara de la burguesía:}

La decadencia de la burguesía encuentra su auge en el personaje Álvaro Mesía, un donjuán seductor y seducido a la vez. Y como que en La Regenta nadie se salva, y de las críticas no se excepciona ni a curas ni a burgueses, estos últimos han de tener el mismo grado de culpabilidad (y de reproche) que de la iglesia en deformar y degradar la moral colectiva. Clarín, siendo él un burgués, odia como su gente abandona su idiosincrasia para hacerse ver aristócrata. Parece que los burgueses piensen de esta manera: si no somos ricos como los aristócratas, al menos podemos ser falsos como ellos, la apariencia es lo único que vale, y no su naturaleza. Esta crítica mordaz no es más que un intento desesperado de Clarín para despertarlos y salvarlos de su propia falsedad. La burguesía se nota en el personaje donjuanesco Álvaro Mesía, en este defensor del catolicismo que paradójicamente odia a Dios: " estos le disgustaron; hablaban mal de la Iglesia y bien del cielo, de Dios, del alma... y precisamente él quería todo lo contrario" (La Regenta, 1999, p. 313). Él es el autor de la caída moral de la única mujer virtuosa en Vetusta, Ana Ozores, pero también es el símbolo de la corrupción política, y si la iglesia es el escondite espacial de Fermín, el casino es el de Mesía, donde desnuda su decadente ideología y desenmascara a la sociedad misma. En una de las descripciones del lugar, el narrador dice " "Los socios jóvenes querían mudarse [ del casino], pero el cambio de domicilio sería la muerte de la sociedad" (La Regenta, 1999, p. 212), esto refleja la resistencia del casino al cambio y a las nuevas reformas a pesar de "sus goteras y demás achaques de abolengo" (La Regenta, 1999, p. 212). El casino personifica la España de la Restauración que por ser tan enferma y pútrido, se mantiene inmóvil y acepta su paralización social. Así que con " Los socios antiguos no hacían caso, ni levantaban los ojos" (La Regenta, 1999, p. 213) el narrador se refiere a la alta burguesía y a la clase clerical, tan contentos con el estancamiento. Entre nuevos y antiguos socios, Álvaro es el personaje usado por Clarín para azotar a ambas partes. De su biografía, puedo citar cuatro datos esenciales: es el jefe de ese casino defectuoso, es el presidente del Partido Liberal, es un mujeriego elegante e hipócrita burgués. Pero también es un hombre vacío y un político sin causa ni ideales. Las mujeres de Vetusta le admiran por su arte de seducir " ante su fantasía el presidente del Casino era todo un hombre de novela " (La Regenta, 1999, p. 237) esto es lo que acrecienta notablemente su frívola popularidad y fuerza infundada frente a sus enemigos. Clarín odia en su personaje esta capacidad de abismar a los presentes y acaparar su atención, le asfixia la seducción asexual que ejerce sin esfuerzo, esta misma que tenía el restaurador Cánovas para persuadir a los políticos y establecer el turno pacifico entre los enemigos clásicos: Liberales y Conservadores. (Arellano, 2004)

\subsubsection{Ana, el ornamento social:}

Ana es la mujer que marca la excepción en el conjunto femenino de Vetusta, no solo por su condición, sino por su fe. Igual que muchas, ella es tratada como un adorno social, tal vez, los 
hombres exorbitan este trato con ella más que con otras debido a su extrema belleza, pero lo que la distingue de las mujeres vetustenses es su despertamiento sensitivo y su conciencia feminista que la conducen a un final trágico: el adulterio. La Regenta es la historia de esta mujer en el seno de la vetusta "Vetusta", que vive en el abismo de las dudas, entre el abnegación- resignación y satisfacción-perdición. Ana es la versión femenina de su autor, en su mecanismo psicológico actúan los mismos componentes que permanecieron fijos en Clarín, a pesar de su famosa heterodoxia. Me refiero a su frustración, desilusión, disgusto, inquietud por el futuro, uno mejor que el presente, por ello, hace que Ana emprenda la acción para cambiar su presente, la del adulterio. Pero aun siguiendo su instinto- si no su libido- ella sale pérdida, machacada y excluida de una sociedad que ella misma se develó para garantizar que Ana cayera en la trampa. ¿Qué alternativas proporciona una sociedad cerrada, inmóvil y bloqueada a una mujer casada con un hombre mayor que la trata como una hija? Un paternalismo inusual en la unión matrimonial, a tal punto de que el marido se enrojece cuando besa accidentalmente a su propia mujer." Él se inclinó para besarle la frente, pero ella echándole los brazos al cuello y hacia atrás la cabeza, recibió en los labios el beso. Don Víctor se puso un poco encarnado; sintió hervir la sangre. " (La Regenta, 1999, p.143). Los vetustenses que circulan la novela están motivados y seducidos por el dinero, Ana es la única excepción de este determinismo que ejerce la nueva estructura sociopolítica. Ella busca felicidad, esta misma que la esquiva desde la infancia, y contra ella confabula astutamente con la hipócrita sociedad. Es consabida la discriminación sexual en Europa del siglo XIX, y aunque no pretendo entrar a fondo en el tema, ya hartamente abordada, veo imprescindible mencionar los siguientes datos de una época remota. Los hombres tienden a iniciar una carrera profesional o, en los peores casos, viajan. ¿Qué salidas tienen las mujeres? obviamente el convento o el matrimonio. Pero incluso este destino predeterminado socialmente tiene rígidos criterios. Una mujer debe ser rica o acomodada para tener buenos pretendientes. Ana Ozores, la protagonista de La Regenta es la hija de un librepensador y una modista, lo que significa que su perfil como novia no es nada excitante, por ser pobre y sin mayestático linaje, “«No se casarían con ella, (...) porque era pobre” (La Regenta, 1999, p. 210). Sin embargo, hay un hombre, Víctor Quintanar, que la quiere por esposa, a esta mujer quien su sublime belleza no le fue suficiente como para tener un abanico de pretendientes. Pero una vez casada, surgen dos hombres, prototipos, de ideologías antitéticas que se combaten para el mismo trofeo, Ana. Irónicamente, son un sacerdote y un donjuán que no buscan más que profanar su cuerpo aprovechando la vulnerabilidad de su alma. Mientras tanto, a Ana Ozores le pesa el apodo que recibió gracias a su marido, la Regenta, y se siente despectivamente reducida a este papel, que fuera del cual tal vez no tenga reconocimiento social. Ella es uno de los tres monumentos de los que Vetusta alardea: la torre de la catedral, el Paseo de Verano y Ana Ozores. Su belleza la convirtió en un ornamento vivo digno de contemplación y admiración, pero a la vez su alma fue descuidada. ¿Quién sabía que pensaba Ana? Ni siquiera hay quien se interesa en conocer su pensamiento porque "como corresponde a una sociedad un tanto artificiosa, los habitantes de Vetusta procuran ocultar sus pensamientos y deseos." (Hernández, 2004). Y aunque los vetustenses nunca se interesan en los pensamientos de Ana, siempre quieren un pedazo de ella, los hombres para entretenerse, y las mujeres para vengarse de esta virtuosa que su presencia les aplasta a todas. $Y$ 
como muchas, Ana era como un objeto puesto en venta, quién pagaba más, lo tendría. Tampoco el matrimonio burgués procuró su salvación, razón por la cual " Clarín arremete contra una religión que no podía ofrecer cobijo a Ana Ozores " (Sarriá, 1974, p. 95). La burguesía comercializó el matrimonio y lo convirtió en un capital negociable, simultáneamente, rehusó la erotización de esta institución, por lo trágico que puede ocasionar tal temeridad sobre los beneficios materialistas. Con esta concepción capitalista, la burguesía coincide una y otra vez con la iglesia, que aboga por un matrimonio únicamente reproductor, desprovisto de sentimientos y voluptuosidad. El amor era el mal que amenaza la fortuna de las familias, por ello, rechazarlo era una necesidad urgente. Desde edad muy temprana, las niñas empiezan a recibir, o escuchar, consejos sobre el tipo de casamiento que deben contratar, es el matrimonio de convivencia. Así es el caso de Ana Ozores, que desde muy niña escuchaba a su tía diciendo que: "es necesario sacar partido de los dones que el Señor ha prodigado en ti a manos llenas." (La Regenta, 1999, p.195). Las dos tías quieren un pedazo de este negocio prometedor. No obstante, ambas rechazan comercializarse a sí mismas. Vean en el matrimonio una cárcel, y dice una de ellas " ni tu tía Águeda ni yo manifestamos nunca afición al matrimonio" (La Regenta, 1999, p.196). Ana sigue el consejo, intenta aprovechar los dones del Señor y se casa con el ex- regente Víctor Quintanar, pero lo que busca ella no era un beneficio económico, sino un refugio social (y sentimental) que pudiera este hombre garantizar, mientras él, irónicamente, busca un ornamento social que le sirve de compañía en las ocasiones. Sin embargo, alrededor de esta belleza giran maliciosamente dos hombres, dos enemigos, uno para acariciar su cuerpo y el otro para seducir su alma. Ana es una mujer casada, y aunque Víctor es más padre que esposo, cualquier intervención ajena en esta unión traería un desastre infausto. Aun así, tanto el burgués como el sacerdote avanzan enérgicamente en su conquista al percibir la ridícula fragilidad de ese matrimonio. Incluso, a Ana no le agrada el contrato (el matrimonio), y como no se puede modificarlo (el divorcio era prohibido), busca otras alternativas. Lamentablemente, a esa mujer, como muchas de su época, tiene solo una, el adulterio, que es según Marx y Engels otra forma de autocomercialización femenina (Sánchez Martín, 2002). Pero ¿quién ganara el trofeo? Aquí tenemos dos opciones: el sacerdote y el burgués. Fermín de Pas es el hombre eclesiástico que siente el peso de serlo para su madre cuando empieza a sentir las primicias del amor por una mujer casada. Aun así, niega la posibilidad de traicionarla, aunque esto signifique ganar a Ana, porque esta es" la otra, una desconocida, un cuerpo extraño que se le había atravesado en el corazón" (La Regenta, 1999, p. 784). Ella es la pasión pasajera y el trofeo reemplazable. Pero tampoco Ana se siente atraída por este "hermano mayor del alma, con quien las penas se desahogan y los anhelos se comunican" (La Regenta, 1999, p. 298). De hecho, descubrir las verdaderas intenciones de su confesor destruyó un pedazo de la fe y la resistencia que tenía, y por ello, terminó siendo una adúltera tempranamente con don Álvaro Mesía, un estratega experto que no se apresura nunca, y deja arder a fuego lento las pasiones prohibidas hasta que su presa, Ana en este caso, caiga por propia voluntad en sus trampas.

\section{CONCLUSIONES}

En definitiva, La Regenta es una novela social y sociológica, porque describe e indaga a la 
vez. Lo social lo tiene en las referencias históricas que envuelven la narración novelesca, y lo sociológico lo encontramos tímidamente infestado sobre esta composición documental por el desenmascaramiento de su naturaleza. Es asombroso cómo un personaje puede ser la expresión de toda una ideología. En Ana vemos la inocencia profanada por la doble seducción: primero, la burguesía y el donjuanismo de Álvaro, y segundo, el egoísmo religioso de Fermín, dos caras de la España del XIX. También lo que percibimos en La Regenta es la decepción que sufre un auténtico revolucionario, un valedor de La Gloriosa, que no encuentra mejor catarsis que mil hojas blancas para descargar su rabia y transformar éstas en una obra imperecedera. En efecto, no es nada extraño que un lector del siglo XIX, y probablemente de otros futuros, encuentre en Vetusta el reflejo de su propia sociedad, porque los ingredientes sociales que configuran La Regenta son universales y perennes. Clarín, sin ser sociólogo y sin optar por técnicas cualitativas, adopta el oficio de un sociólogo y trata Vetusta como si fuera un cadáver, sometiendola a una autopsia que nos desvela los más hondos vicios de una sociedad inmóvil, áspera y discretamente vulgar. Lo dicho anteriormente asevera que la relación entre ambos polos novela- sociología es sumamente recíproca. Esta correspondencia es la prueba de que por una parte existen sociólogos que novelan, y por la otra, novelistas que escriben sociología.

\section{REFERENCIAS}

Alas, L.(1999)( ed.Fuentes, V). La Regenta. AKA.

Alas, L.(2012)( ed.Oleza, J). La Regenta. Cátedra.

Arellano, J, Á (2014). Historia y sociedad en Vetusta. :

https://cvc.cervantes.es/literatura/clarin espejo/avila.htm

Blois, J, P. ( 2014). ¿Para qué sirven los sociólogos? La definición de la sociólogo legítima en textos canónicos de la disciplina y la expansión de las inserciones laborales de los sociólogos. https://ri.conicet.gov.ar/bitstream/handle/11336/34125/CONICET Digital Nro.944164690526-4895-806d-cae5acf941d1 A.pdf?sequence=2\&isAllowed $=y$

Caro Baroja, J. ( 2008). Historia del anticlericalismo español. Caro Raggio

Sarriá, F, G. 1975. Clarín o la herejía amorosa. Gredos.

Gaspa, S. ( 2009). El sociólogo como novelista y el novelista como sociólogo. Revista Espanola de Sociologia. January 2009

Hernández, M, Á . (2004). La sociedad. Psicología y mecanismos de evasión de Ana Ozore. Leopoldo Alas "Clarín" en su centenario (1901-2001): espejo de una época. https://cvc.cervantes.es/literatura/clarin espejo/alvarez.htm

De Espinosa, Emilio, L. ( 2019). Sociología y literatura como formas de conocimiento social. Anales de la Real Academia de Ciencias Morales y Políticas, № 96.

Bártová, M. (2016). Anticlericalismo en La Regenta. [Tesis doctoral en Lenguas y Literaturas Románicas. Universidad de Masaryk.]

Moliner Prada, A.( 2011). Clericalismo y anticlericalismo en la España contemporánea. História: Questões \& Debates. Vol. N55. https://revistas.ufpr.br/historia/article/viewFile/26528/17688

Subero, E. (1974). Para un análisis sociológico de la obra literaria. Thesaurus : Boletín Del Instituto 
Caro y Cuervo, 29(3), 489-500

http://bibliotecadigital.caroycuervo.gov.co/493/1/TH $29003081 \quad 0 . p d f$ 